\title{
NEOPLATONISMO E ARISTOTELISMO NO HILEMORFISMO UNIVERSAL DE IBN GABIROL (AVICEBRON)
}

\author{
Cecilia Cintra Cavaleiro de Macedo*
}

RESUMO - Este artigo discute a presença neoplatônica e aristotélica na metafísica de Ibn Gabirol. Para tanto, são confrontadas as teorias de Plotino e Gabirol, em alguns dos pontos principais, nos quais a semelhança já foi apontada: o Primeiro Princípio, o intermediário entre Deus e o mundo e a questão da matéria universal. Identificadas as diferenças entre as propostas daqueles autores quanto ao tratamento destas questões, serão apresentadas brevemente algumas contribuições que podem ter sido provenientes das obras de Aristóteles, visando esclarecer a origem do tratamento conferido a estes temas por Ibn Gabirol. Acreditamos que a obra de Ibn Gabirol deva ser entendida inserida em seu contexto histórico-filosófico, que primava por ver as doutrinas de Platão e Aristóteles, não como conflitantes, mas como complementares, bem como no sentido de sua compatibilização com o criacionismo abrahâmico que, no caso, obedece ao primado judaico da dessemelhança radical entre Deus e a criação.

PALAVRAS-CHAVE - Ibn Gabirol. Hilemorfismo Universal. Aristóteles. Substância. Matéria Inteligível.
ABSTRACT - This article discusses neoplatonic and aristotelian presence in Ibn Gabirol metaphysics. With this aim, Plotinus and Gabirol's are confronted in some of the main points, where the resemblance had already been pointed: the First Principle, the intermediary between God and the world and the universal matter. Once the differences between the approaches of these authors regarding such questions have been identified, some contributions which may come from the works of Aristotle will be briefly presented, in order to clarify the origin of Gabirol's ideas. We believe that Gabirol's metaphysics must be understood in its historical-philosophical context, characterized by a view of Plato and Aristotle's doctrines not as conflicting but complementary, as well as in its effort of harmonize them with the abrahamic creationism which, in this case, obeys the Judaic primacy of radical separation between God and the creation.

KEY WORDS - Ibn Gabirol. Universal Hylemorfism. Aristotle. Substance. Intelligible Matter.

Ao pensarmos a filosofia medieval para além das fronteiras do Cristianismo, mais especificamente em terras dominadas pelo Islam, ${ }^{1}$ temos a tendência a iden-

PUCSP/São Camilo.

Vale ressaltar que aqui nos referimos ao critério político-geográfico, não nos referindo à filosofia Islâmica, mas à filosofia desenvolvida em terras que se encontravam sob o domínio islâmico, não importando a origem religiosa dos pensadores. "A denominação filosofia árabe parece-me um tanto inexata, pois, se tomada no sentido lingüístico, nem toda ela utilizou como veículo de expressão o idioma árabe, e Avicena, por exemplo, utilizou indistintamente o árabe e o persa. Se, ao contrário,

\begin{tabular}{|l|l|l|l|l|l|}
\hline VERITAS & Porto Alegre & v. 52 & n. 3 & Setembro 2007 & p. 132-148 \\
\hline
\end{tabular}


tificá-la, num primeiro momento, com a Falsafa, ou com o que nos acostumamos a chamar deste modo, no sentido de reconhecer somente aqueles autores que auxiliaram na transmissão das idéias de Aristóteles ao contexto latino. Ao lado desta, vemos uma franja de filosofia mística de cunho neoplatônico e neopitagórico e ainda uma tradição teológica racional representada pelo Kalam. Não raramente, estas últimas nos parecem de menor importância para o estudo do desenvolvimento das idéias filosóficas na Idade Média, a não ser por sua influência nos autores referidos. Há que ter em mente que, mesmo a Falsafa, entendida enquanto aquela parcela da filosofia em terras do Islam praticada especificamente pelos filósofos helenizantes, ${ }^{2}$ não consiste em um movimento homogêneo, qual uma Escola de pensamento, mas congrega em si uma série de variantes que vão desde um aristotelismo praticamente puro, ${ }^{3}$ dos filósofos "entusiasmados com os peripatéticos" ${ }^{4}$ a um neoplatonismo perpassado por idéias pré-socráticas.

Mesmo entre os Falasifa, mais conhecidos, considerados racionais e de tendência aristotelizante, podemos ver aqueles que se mantinham numa eqüidistância entre o aristotelismo e o neoplatonismo, e também muitos deles desenvolveram paralelamente, algum interesse em outro tipo de conhecimento que não pode ser expresso adequadamente em moldes racionais. Do mesmo modo, boa parte dos pensadores mais "místicos" ou "platonizantes" mantinham algum traço de contato com a demonstração lógica e com conceitos e idéias fundamentais formulados ou desenvolvidos por Aristóteles, e que vieram a fazer parte do fundo comum de conhecimento da época. ${ }^{5}$ Assim, a separação total entre essas "correntes de pensamento" é muito difícil, no âmbito islâmico, especialmente até ao século XII ou XIII, posto que também o misticismo atravessa a própria filosofia. Há que lembrar que "no Islam, Falsafa foi entendida imediatamente como uma palavra grega, e continua a sê-lo. A palavra é decomposta e explicada por Al-Kindi que propôs, a seguir, diversas definições paralelas àquelas que se encontram nos co-

com o termo árabe quisermos fazer referência a um suporte étnico, o erro é ainda maior, pois poucas gotas de sangue árabe correram pelas veias de Avicena e Averróis. Por isso, em meus trabalhos, preferi sempre a expressão filosofia muçulmana. Mas esta denominação tampouco é absolutamente correta, pois o Islam, assim como o Cristianismo, não tem porque possuir uma filosofia própria" (CRUZ HERNÁNDEZ, Miguel. La Filosofía Árabe. Madrid: Revista de Occidente, 1962. Prólogo, p. xviii).

2 "Aplica-se a denominação de "filósofos helenizantes" ao grupo dos falasifa (plural de faylasuf, transcrição árabe do grego philosophos), os únicos os quais, convencionalmente, vieram sendo considerados como representantes daquilo que no Islam poderia ser a filosofia. O que, até aqui dissemos, dispensa-nos de insistir em que tal restrição é completamente abusiva e procede de uma idéia preconcebida" (CORBIN, H. Historia de la Filosofía Islámica. Madrid: Trotta, 2000, p. 147).

3 Contaminado apenas pelos textos de atribuição arbitrária.

4 Conforme a estes se refere o próprio Avicena no Prólogo ao Shifa (cf. CRUZ HERNÁNDEZ, "Estudio Preliminar". In AVICENA. Tres estudios esotéricos. Madrid: Tecnos, 1998, p. xxix).

5 Quanto a essa questão, os "escritos visionários" de Avicena ilustram bem o primeiro processo, bem como, conforme Corbin, o próprio Al-Farabi apresenta influxos do sufismo em sua obra, e "há, nas Gemas [da sabedoria ou Fusus al-Hikam], senão em outros lugares, um texto que soa como um eco do êxtase plotiniano no livro da Teologia". (CORBIN, op. cit., p. 153). 
mentadores gregos de Aristóteles". ${ }^{6}$ Mais do que a autores, podemos dizer que o que entendemos por Falsafa corresponde a um conjunto de textos. Conforme Leaman,

é difícil salientar o significado daquilo que pode ser chamado de misticismo no mundo filosófico islâmico. Praticamente todos os grandes pensadores escreveram sobre tasawwuf (misticismo), ou ao menos expressaram algum interesse nisso. (...) Esse interesse no misticismo levou alguns comentadores a descreverem a filosofia islâmica como tendo incorporado a idéia de que é impossível buscar a sabedoria sem ao mesmo tempo buscar a Deus. Isto é, a filosofia islâmica é tida como muito mais holística que a filosofia ocidental, que vê a si mesma freqüentemente como uma investigação técnica de conceitos particulares que empregamos em nosso pensamento. ${ }^{7}$

Nesse sentido, não estaríamos distantes da realidade, ao supormos que a originalidade de cada um destes filósofos que desenvolveram seus estudos em terras dominadas pelo Islam, é revelada precisamente no modo de composição entre platonismo e aristotelismo, por um lado, e entre filosofia racional e mística, por outro.

Dentro desse quadro, não é surpreendente que autores, como Schlomo Ibn Gabirol, apresentem uma filosofia que segue a estrutura neoplatônica das emanações exposta através de conceitos aristotélicos, ao lado de uma produção poética místico-filosófica que, de algum modo, ajuda a esclarecer seu modelo metafísico. Schlomo Ben Yehuda Ibn Gabirol é uma personalidade multifacetada que chegou até nós como poeta, filósofo, gramático e exegeta. Apresentando em sua filosofia um modelo sensivelmente diferente de seus contemporâneos islâmicos, no qual a totalidade dos seres criados constitui-se de um composto hilemórfico proveniente da Vontade divina, nega a eternidade da matéria e não estabelece uma hierarquia de inteligências e esferas, mas um conjunto de intermediários inteligíveis entendidos como substâncias simples entre a Vontade de Deus e a substância corpórea, para as quais a eternidade é uma duração temporal, assim como propõe um processo de retorno que só é completado através da graça de Deus.

\section{O Neoplatonismo de Ibn Gabirol}

A teoria gabiroliana já foi exaustivamente associada ao modelo plotiniano. Conforme Brunner, um editor das Quaestiones Disputatae de Anima, "comenta que Avicebron ensina um panteísmo derivado de Plotino e exerce uma influência perniciosa sobre grande número de filósofos da Idade Média". ${ }^{8}$ Munk afirma que,

${ }^{6} \quad$ BRAGUE, Remi "Sens et valeur de la philosophie dans les trois cultures médiévales". In Miscellanea Mediaevalia ed. Jan A. Aertsen, Band 26: Was ist Philosophie im Mittelalter. Berlin: Walter de Gruyter, 1998, p. 230.

7 LEAMAN, Oliver. An Introduction to Classical Islamic Philosophy. Cambridge University Press, 2002, p. 191.

8 Ed. F. Hedde, Paris, 1912, p. 91, nota 2, apud BRUNNER, Fernand. Platonisme et aristotelisme - La critique d'Ibn Gabirol par S. Thomas d'Aquin. Publications Universitaires de Louvain, 1965, p. 34. 
apesar de serem notórias as influências do peripatetismo árabe, "a influência que predomina na filosofia de Ibn Gabirol é a das doutrinas neoplatônicas", , em especial, a da Escola de Alexandria, e que ele teria sido erroneamente considerado "o primeiro que reconheceu uma matéria para a alma e para as outras substâncias simples", ${ }^{10}$ dado que neste ponto ele estaria de acordo com Plotino. ${ }^{11}$ M. Joël vai além, afirmando que sua obra filosófica, o Fons Vitae não passa de "um compêndio de filosofia neoplatônica". ${ }^{12}$

Ainda que Munk insistisse em conectar o pensamento do autor diretamente ao pensamento plotiniano, fato este que acabou por conduzir à caracterização da doutrina de Ibn Gabirol como um panteísmo emanatista, na mesma época, já A. Franck discutia essa tese, compreendendo a filosofia gabiroliana como uma tentativa bastante bem-sucedida de integrar o hilemorfismo aristotélico, a concepção alexandrina e a presença de um Deus pessoal acima da emanação. ${ }^{13}$ Mais adiante, G. Vajda também questionaria essa suposta dependência de Ibn Gabirol para com as idéias de Plotino, afirmando que "em muitos pontos ela se afasta sensivelmente da doutrina comum de Plotino e seus sucessores; sua rígida máscara de objetividade filosófica não oculta completamente suas preocupações teológicas". ${ }^{44} \mathrm{E}$. Bertola ${ }^{15}$ irá minimizar mais ainda estas influências, apontando como fontes diretas seguras a Teologia de Aristóteles, o Pseudo-Empédocles e a tradição neoplatônica árabe.

As associações com o modelo plotiniano giraram em torno de diversos pontos, bem como de uma série de imagens comuns utilizadas pelos autores. Dentre esses pontos, serão abordados neste texto: a transcendência e inefabilidade do Primeiro Princípio, a doutrina da Vontade como intermediária, a questão da matéria universal primeira e matéria espiritual.

Quanto à questão do Primeiro Princípio, o tratamento conferido à Essência Primeira (o Deus gabiroliano) apresenta-se com diferenças fundamentais quanto ao

9 MUNK, S. Mélanges de Philosophie Jüive et Arabe. Paris: Librairie philosophique J. Vrin, 1927, p. 235.

$10 \quad$ Ibidem, p. 238.

11 Para defender essas afirmações, Munk apóia-se fundamentalmente na segurança, pois argumenta que a Teologia de Aristóteles, que se descobriu ser composta fundamentalmente de textos extraídos das Enéadas, seria o único texto disponível na época de Gabirol. Mais tarde, com a publicação de uma versão do texto da Teologia por Dieterici, Jakob Guttman questionou o argumento de Munk, com base no fato de que todas as referências à Palavra de Deus tinham sido suprimidas no texto árabe. (GUTTMAN, J., Die Philosophie des Salomon Ibn Gabirol. Göttingen, 1889, p. 31).

12 JOËL, M. Ion Gabirols (Avicebrons) Bedeutung für die Geschichte der Philosophie, Monatsschrift für Geschichte und Wissenschaft des Judentums, VI, 7, comentado por Julius Guttman, que atribui esta interpretação ao fato de que Joël nada mais faz senão remontar as teses individuais do livro às antigas fontes neoplatônicas. (GUTTMAN, Julius. A filosofia do Judaísmo. São Paulo: Perspectiva, 2003, p. 114, nota 25).

13 FRANCK, A. Dictionnaire des Sciences Philosophiques. Paris, 1975, 127-131, apud LERTORA MENDOZA, Celina Ana. El Legado de Sefarad: Temas de Filosofía Sefardí. Buenos Aires: Editorial Sefarad 92. 1999.

14 VAJDA, G. Introduction à la pensée juive au Moyen Âge. Paris: J. Vrin, 1947, p. 76.

15 BERTOLA, Ermenegildo. Salomon Ibn Gabirol, Vita, Opere e pensiero, Padova: Casa Editrice Dott. Antonio Milani (CEDAM), 1953, p. 50 et seq. 
Uno plotiniano. Para Ibn Gabirol, a Essência Primeira é absolutamente transcendente, sendo inatingível em si mesma pelos seres humanos. Com essa afirmação, ele tenta enquadrar sua doutrina emanatista na linha-mestra do pensamento hebraico - a radical dessemelhança entre Deus e a Criação - cuja defesa colocá-lo-á, de fato, muito distante do panteísmo ao qual foi eventualmente associado. Gabirol inicia sua obra deixando patente esta separação intransponível e a total falta de continuidade entre Deus e a Criação, utilizando-a inclusive como argumento principal para a sustentação de sua defesa da existência necessária de intermediários entre a substância que sustenta a corporeidade (da qual provêm todos os seres sensíveis compostos de matéria física associada à forma) e a Essência Primeira. A aparente semelhança, que residiria no fato de o Uno plotiniano ser situado acima do ser e acima do pensamento, conforme nos apresenta nas Enéadas, tem claro antecedente em Fílon de Alexandria, bem como a utilização freqüente de metáforas positivas, alternando-se com a repetida advertência sobre sua transcendência e inefabilidade. ${ }^{16}$ Mas o Uno plotiniano é uma realidade que cria a si mesma, sendo autoprodutora $^{17}$ e produtora da multiplicidade, e ainda admite a pergunta por que ele é o que é, e a conseqüente resposta porque ele assim o quer, unificando-se assim sua Essência e sua Vontade.

Para Gabirol, assim como, por razões diversas, tanto para Aristóteles quanto para o criacionismo abrahâmico, em geral, esta questão é por si absurda. O Uno plotiniano cria por transbordamento e superabundância; para Gabirol, Deus, ou a Essência Primeira, cria por vontade livre e graça, conforme é reforçado pelo texto do poema Keter Malkut, quando diz: "Pois me criaste, não por necessidade, mas por generosidade; não por força, mas por amor e graça". ${ }^{18}$ Sob outro aspecto, o Uno plotiniano é amável e é amor, enquanto a Essência Primeira de Ibn Gabirol é tão inefável que não pode ser objeto de amor. O trecho das Enéadas citado a seguir expressa, de forma resumida, algumas das diferenças que tencionamos ressaltar:

Ele, porém, possui o lugar supremo - na verdade não possuindo, mas sendo ele mesmo o vértice - Ele tem sujeitas as coisas na sua totalidade, não vindo a elas; são elas que vêm a Ele; mais ainda, os outros seres estão em torno dele, mas não é Ele quem volta o olhar para eles, mas eles que O contemplam. Ele é, por assim dizer, transportado ao interior de si mesmo, amando a si mesmo e sua pura luz, sendo ele mesmo idêntico ao que ama... ${ }^{19}$

No parágrafo citado, Plotino apresenta o Uno como vértice das coisas que existem. Para Ibn Gabirol, a Essência Primeira é absolutamente separada da criação, não podendo ser conduzida ao lugar de vértice, ou a qualquer posição defini-

\footnotetext{
${ }^{16}$ Ver como exemplo, PLOTINO, Enéada Quinta. Traducción del griego, prólogo y notas de José Antonio Míguez. Buenos Aires: Aguilar, 1967, 3,15, em contraposição a 3, 13.

17 PLOTINO, Eneada Sexta. Traducción del griego, prólogo y notas de José Antonio Míguez. Buenos Aires: Aguilar, 1967, 8, 13.

18 IBN GABIROL, Keter Malkut, canto XXXV.

19 PLOTINO, Eneada Sexta, 8, 16.
} 
da em relação aos seres criados. No modelo gabiroliano, as coisas que existem, reduzem-se necessariamente a duas raízes (matéria e forma), posto que, "se a raiz de todas as coisas diversas fosse uma, seria preciso que naquilo em que concordam houvesse diversidade; e ainda que a raiz de tudo fosse uma, seria preciso, entretanto, torná-la duas em sua própria raiz". ${ }^{20}$ Essas duas, por sua vez, reúnemse na Vontade. ${ }^{21}$

A Essência Primeira não faz parte desta seqüência. Se fosse possível um vértice único (o que é questionável, dado que a criação, desde o seu início, se resume a duas raízes), este seria ocupado, no modelo de Ibn Gabirol, pela Vontade. Esta, em contraposição ao modelo de Plotino, não é de modo absoluto idêntica à Essência, mas o é somente enquanto considerada em potência e sob a perspectiva da Essência. Em ato ou sob a perspectiva das criaturas, ela é distinta da Essência e é a verdadeira unidade criadora. Por outro lado, tampouco pode ser considerada propriamente uma primeira emanação separada; esta seria a inteligência, já composta de matéria e forma. A Vontade em si não é sequer a forma da inteligência, mas ela a contém também em potência e de um modo absolutamente simples.

Como poderia não ser a Vontade distinta da matéria e da forma, quando ela é autora e a matéria e a forma são criadas? Além disso, quando considerada separada de sua ação, a Vontade é una com a essência, e quando é considerada em sua ação, é distinta da essência, de acordo com o que diferem em si no princípio da criação, isto é, no início da união da matéria e da forma. ${ }^{22}$

Por outro lado, a inefabilidade da Essência Primeira gabiroliana não impede o seu olhar para as criaturas. A semelhança aparente com a linguagem plotiniana, que pode ser abstraída do termo olhar, também não passa da imagem platônica, dado que, para Ibn Gabirol, são sempre as realidades superiores que olham para as inferiores, enquanto olhar das causas aos efeitos, conforme verificamos nesta passagem:

Isso ocorre, porque as coisas não são da mesma maneira nos superiores como elas são nos inferiores, pois as formas são mais perfeitas e mais plenas nas causas que

${ }^{20}$ IBN GABIROL, Fons Vitae, I, 6. Todas as citações do texto do Fons Vitae são de tradução nossa a partir de AVENCEBROLIS (IBN GABIROL) Fons vitae/ex Arabico in Latinum translatum ab Iohanne Hispano et Dominico Gundissalino; ex codicibus Parisinis, Amploniano, Columbino primum edidit Clemens Baeumker. Münster: Aschendorff, 1895.

21 "E mais, as coisas se reduzem ou a duas raízes ou a várias, ou a outra divisão. Dessa maneira, como o corpo está situado na extremidade inferior, composto de matéria e de forma, opõe-se à Inteligência, a qual está na extremidade superior, a inteligência se compõe também de matéria e de forma, pois o inferior é emanado do superior; e também assim fica claro que tudo é composto de matéria e de forma. De todas estas maneiras podemos demonstrar que existe uma matéria universal e uma forma universal. Lembra-te, pois do que dissemos do ser da matéria e da forma universal desde o início de nossa discussão até este momento, porque por este caminho chegarás ao conhecimento do ser da matéria universal e da forma universal". (Ibidem, V, 12).

22 Ibidem, V, 37. 
nos efeitos, dado que se produzem nos efeitos somente pelo olhar das causas aos efeitos. $^{23}$

Mesmo Deus é aquele que olha; não é, como o Uno plotiniano, um objeto de contemplação para o qual os olhares se dirigem na busca do retorno. Ainda que, a partir da passagem "por isso foi dito que tudo nasce da sabedoria de Deus Excelso, por seu olhar, por seu mandato e outras coisas semelhantes", ${ }^{24}$ pudéssemos imaginar que a criação ocorreria por um olhar dos superiores aos inferiores, partindo da Essência Primeira, e que o retorno seria o movimento contrário, notamos que, para Ibn Gabirol, tudo é um e o mesmo movimento; tanto a criação quanto o retorno dependem diretamente do olhar de Deus. Isso pode ser claramente verificado, a partir do trecho final do livro, no qual ele é bastante claro no que se refere ao objetivo final: "pois quando fizeres isto, Ele te olhará com bondade e será generoso contigo". 25

Por último, do mesmo trecho citado, podemos sublinhar na visão de Plotino, a idéia de que este retorno é o Uno "transportado ao interior de si mesmo, amando a si mesmo (...) sendo Ele mesmo idêntico ao que ama". Temos aqui uma afirmação nitidamente panteísta que não concorda com a teoria de Ibn Gabirol. A absoluta transcendência, a separação e a relativa incompreensibilidade de Deus são totalmente preservadas no modelo gabiroliano, como já foi apontado. Em nenhum momento do Fons Vitae, Gabirol sugere qualquer identidade entre Deus e a Criação, ou, de acordo com sua terminologia, entre o composto hilemórfico e a Essência Primeira, ou mesmo qualquer tênue semelhança, continuidade ou sequer contigüidade. Pelo contrário, o Deus de Gabirol é incognoscível pelo esforço humano, seguindo fielmente a tradição judaica que advoga que a possibilidade de conhecimento ocorre através de suas obras, e não de modo completo, em virtude de sua infinitude: "Por que é impossível o conhecimento da essência? Porque está acima de tudo e porque é infinita". ${ }^{26}$ Esse argumento é reforçado ainda pela necessidade do olhar de Deus para completar o processo de conhecimento, conforme citado no parágrafo anterior.

Quanto à teoria gabiroliana da Vontade, particularmente, tendemos a concordar com McGinn, quando aponta que:

Pode-se pensar que a Vontade Divina de Ibn Gabirol funciona como o "Unomuitos" do Nous plotiniano, mas as diferenças são mais evidentes que as similaridades. Abordando o problema subjacente da origem da multiplicidade na unidade, a Voluntas é tanto criadora (o Factor Primus precisamente como Criador) quanto derradeira unidade (prima unitas). ${ }^{27}$

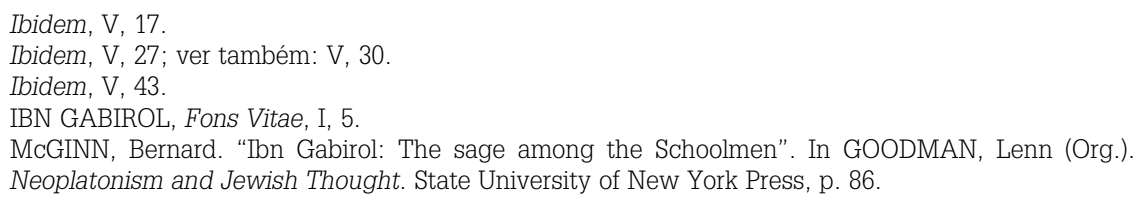


A função da Vontade divina pode ser explicada no modelo de Gabirol da seguinte maneira: como entre dessemelhantes não pode haver ligação direta, estes pólos têm necessidade de um ou mais intermediários entre eles. Estes deverão ser necessariamente semelhantes, de algum modo, a um e a outro. Assim, a Vontade serve de intermediário, sendo idêntica à Essência Primeira e inseparável daquela enquanto atributo seu, enquanto é também semelhante à forma e à matéria em sua ação, no sentido de que as contém em potência. A Vontade funciona no modelo gabiroliano como separação e ligação entre Deus e a Criação, e possui, portanto, um duplo status: o primeiro em essência, ou seja, em si mesma e em relação a Deus; e o segundo em ato, enquanto criadora e autora de todas as coisas e de seus movimentos. Se entendida em relação à Essência Primeira, apresenta-se o primeiro status: "A Essência Primeira e Santa, ela mesma e sua propriedade formam uma unidade sem distinção" ${ }^{28}$ e se considerada do ponto de vista da criação, ou seja, da matéria e da forma, assume o segundo status: "É uma virtude divina que cria a matéria e a forma e as une, que se infunde desde o mais alto até o mais baixo". ${ }^{29}$

Certo é que esse tema não é novidade, posto que figura como problema central a ser resolvido, a partir do pensamento platônico e ao qual diversos autores se propuseram oferecer suas soluções. A intermediação que funciona de modos diferentes, caso seja considerada a partir de Deus ou a partir da criação, tal como propõe Gabirol, consta já da discussão, desde a proposição do Lógos de Fílon de Alexandria e adentra como tema comum aos neoplatônicos tardios. A obscuridade que cerca o Lógos filoniano é, em grande parte, devida à dificuldade que aquele autor apresentou em explicitar estes dois modos de consideração. Potência de Deus a mais elevada, refere-se ao Lógos em diferentes passagens e contextos e a partir de diferentes pontos de vista, o que gera o cerne desse problema de interpretação. Em algumas passagens, parece coincidir com a atividade pensante de Deus e, dessa maneira, não é distinto do próprio Deus. Mas, em outras passagens, é atributo separado cuja função é criar as realidades inteligíveis. Ora, Ibn Gabirol utiliza o mesmo tipo de descrição com relação à Vontade (a qual é também denominada por ele como Verbo, ou Lógos), quando entendida de acordo com a perspectiva do criador, e não da criação:

Tua dúvida procede da suposição de que a Vontade é infinita. Mas, ainda que a Vontade seja infinita se considerada na essência sem a ação, não deve sê-lo segundo sua forma defluida, porque sua ação é finita, porquanto possui um início e porquanto a forma começa a partir dela. Como ela é princípio da forma que dela deflui, deve ela mesma ser finita no princípio de sua ação enquanto princípio da forma que dela emana. Logo a Vontade deve ser intermediária entre a essência altíssima e a forma que deflui da Vontade. Mas, quando considerada em si mesma,

\footnotetext{
28 IBN GABIROL, Fons Vitae, V, 42.

29 Ibidem, V, 38.
} 
e não por sua ação, a Vontade então não será nem intermediária nem finita, mas ela mesma e a Essência são idênticas. ${ }^{30}$

Além disso, quando considerada separada de sua ação, a Vontade é una com a Essência, e, quando é considerada em sua ação, é distinta da Essência, de acordo com o que diferem em si no princípio da criação, isto é, no início da união da matéria e da forma. ${ }^{31}$

Filon entende o Lógos como lugar ${ }^{32}$ lógico das Idéias, no sentido de que as contém. A concepção de Vontade como lugar também é utilizada por Ibn Gabirol, para quem a forma é o lugar inteligível da matéria, posto que a sustenta, sendo a Vontade o lugar inteligível para ambas:

Diz-se que a matéria é o lugar da forma, a partir do conceito, isto é, de que a sustenta e se sustenta nela. Da mesma maneira, dizem que a Vontade é o lugar de ambas ao mesmo tempo, de uma e de outra. O que se depreende disso é que cada uma delas necessita da Vontade para possuir o ser e subsistir. Mas o verdadeiro lugar se dá na extremidade inferior da forma. E o mesmo se deve dizer do tempo. Já te esclareci anteriormente que o lugar pode ser de dois modos: espiritual e

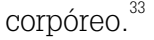

A questão da matéria primeira universal já foi associada a algumas idéias expostas nas Enéadas, como a existência de uma matéria Prima como uma das primeiras hipóstases, e a admissão da existência da matéria inteligível, a qual seria modelo da sensível. Esta semelhança aparente poderia ser deduzida de passagens como a seguinte:

Assim também a matéria, se ela existe desde a eternidade, é impossível que ela não participe, justamente em razão desse seu existir, da potência que a todos dá o bem, tendo como único limite a possibilidade de cada um. Mas se também o seu nascimento é só uma conseqüência necessária de causas anteriores, nem mesmo nesse caso ela deve ser separada do seu princípio, como se esse, que no momento lhe concedeu graciosamente o existir, devesse subitamente deter-se por impotência, antes de alcançá-la. ${ }^{34}$

Mas, podemos notar, na mesma passagem citada, já uma grande diferença: para Gabirol a matéria não existiu sempre. Enquanto criada, ela não pode ter existido sempre ou ser infinita, pois tudo o que é criado difere radicalmente de seu Criador. Desse modo, ela tem começo e fim, e seus limites próprios. Quanto à existência da matéria inteligível, também é defendida por Plotino, o qual afirma que "também, nos seres inteligíveis, a matéria é igualmente o ilimitado e pode ser

\footnotetext{
IBN GABIROL, Fons Vitae, IV, 19.

Ibidem, V, 37.

Em De Opificio Mundi 24, escreve que "o mundo constituído pelas Idéias não podia ter outro lugar senão o Logos divino, que organizou esta realidade. Que outro lugar poderia haver senão a Potência de Deus que fosse capaz de acolher e conter, não digo todas, mas uma única Idéia como essa?".

IBN GABIROL, Fons Vitae, V, 31

PLOTINO, Enéada Sexta, 8, 6.
} 
gerada a partir da infinidade do Uno ou do seu poder ou da sua eternidade; não que o indeterminado encontre o Uno, mas ele o produz". ${ }^{35}$ Mas a matéria inteligível em Plotino tem características próprias do inteligível, que vêm a ser a simplicidade, a imutabilidade e a eternidade, ao passo que a sensível revela características opostas. Gabirol, ao contrário, não faz essa diferenciação radical entre os dois tipos de matérias, mas afirma, diversas vezes, sua unidade absoluta na matéria universal. A diferença se torna mais clara pela seguinte passagem das Enéadas, que exemplifica a necessária contradição entre a matéria inteligível e a matéria sensível, além de apontar para outras questões divergentes, como a impossibilidade de diversas formas concomitantes no mesmo sujeito.

Nos seres inteligíveis existem seres compostos, sem que isso queira dizer que tenham um corpo (...). Por outro lado, a matéria dos seres engendrados recebe constantemente umas e outras formas, enquanto que a matéria dos seres eternos é sempre a mesma. Quanto à matéria daqui, ocorre o contrário: aqui, efetivamente, todas as formas deverão ser consideradas como partes, ainda que em cada momento só exista uma que apenas subsiste por algum tempo, porque é rechaçada pela outra. Por isso, aqui nada permanece idêntico, enquanto que no mundo superior todas as coisas formam um conjunto; lá a matéria não precisa transformarse, porque possui já todas as formas e jamais, diremos, se encontra privada dela. ${ }^{36}$

Não existe quebra alguma de continuidade na seqüência de estruturas matéria/forma por toda a criação. A aparente oposição entre matéria inteligível e hylé é provocada pela limitação da percepção sensível, pois, do ponto de vista do entendimento, não há separação radical. Recordando os graus de subsistência apontados por Ibn Gabirol, notamos que não há em absoluto descontinuidade em si, mas somente frente à nossa própria percepção:

As coisas que existem subsistem em nove graus: o primeiro destes é a subsistência de todas as coisas no conhecimento do Criador; abaixo dele a subsistência da forma universal na matéria universal; abaixo deste, a subsistência das substâncias simples umas nas outras; abaixo disto, a subsistência dos acidentes simples nas substâncias simples; abaixo deste a subsistência da quantidade na substância, abaixo deste a subsistência das superfícies no corpo, das linhas na superfície e dos pontos na linha; abaixo disto a subsistência das cores e das figuras na superfície; abaixo disto a subsistência de algumas partes dos corpos homogêneos em outras partes e abaixo disto a subsistência de alguns corpos em outros corpos, e este é o lugar conhecido. ${ }^{37}$

Os graus, desde a Sabedoria do Altíssimo até ao mais vil suporte das categorias, sucedem-se sem rupturas. Plotino aponta ainda uma necessária visão do distanciamento progressivo como "queda", o que leva à associação desta distância com o mal. Essa visão não aparece em momento algum na obra de Gabirol,

\footnotetext{
${ }^{35}$ PLOTINO, Enéada Segunda. Traducción del griego, prólogo y notas de José Antonio Míguez. Buenos Aires: Aguilar, 1972, 4, 15.

36 PLOTINO, Enéada Segunda, 4, 3.

${ }^{37}$ IBN GABIROL, Fons Vitae, II, 14.
} 
sendo o mal um dos temas que não se apresenta, em absoluto, em qualquer parte de sua filosofia.

Verificamos que, apesar de a Materia Prima ser, em certo sentido, a primeira hipóstase para ambos os autores, o processo é qualitativamente diferenciado. Enquanto para Plotino a matéria indeterminada é a alteridade inteligível que se determina voltando-se para o Uno, para Gabirol, a matéria primeira e a forma primeira são criadas simultaneamente e, portanto, a forma (que determina a matéria) diferencia-se da Vontade no mesmo "instante" da criação da matéria com a qual irá posteriormente se associar. Num outro momento do texto, afirma que a matéria é criada pela própria essência, enquanto que a forma primeira o é pela sua propriedade, tendo existido antes na sabedoria de Deus, ainda que a propriedade seja intrínseca à Essência e não algo exterior a ela:

$D$ - Tornemos a falar do que antes nos ocupávamos, isto é, de que todas as formas, que subsistem na matéria são impressões da sabedoria da essência primeira e, supondo que isso dizemos da forma, que diríamos da matéria?

$M$ - Da matéria dizemos o mesmo que da forma, isto é, que a matéria é criada pela essência e a forma pela propriedade da essência, isto é, pela sabedoria e pela unidade, ainda que a essência não seja determinada por propriedade extrínseca a ela. Esta é a diferença entre o criador e o criado, porque o Autor é a essência essencial e o que é criado compõe-se de duas essências, que são a matéria e a for$\mathrm{ma}^{38}$

Quanto ao movimento da matéria indeterminada, quando se dirige à sua determinação, esse não é em direção ao Uno (quer seja este entendido como equivalente da Essência Primeira ou da Vontade), mas à forma em si, já enquanto forma, e não em sua existência potencial na Vontade: "Disso se deduz que, posto que a matéria primeira é móvel, seu movimento seja em direção a outro, isto é, em direção à forma, para obtê-la e aperfeiçoar-se através dela. Portanto, é necessário que antes carecesse dela". 39

Plotino denomina o Nous com expressão filoniana, cosmo inteligível, mundo da ordem e da harmonia espiritual, portanto, mundo da beleza. Para Plotino, com efeito, a beleza em geral coincide com a forma: uma coisa é bela segundo o quanto possui de forma, entendendo a matéria (ao menos a matéria sensível) como causa das imperfeições e fealdades. Essa contraposição entre matéria e forma como princípios da imperfeição e da beleza não há em Ibn Gabirol, cujo objetivo fundamental no Fons Vitae não é libertar-se da matéria mantendo a forma, porém chegar à matéria universal: ${ }^{40}$ "Mas se te alçares até à matéria primeira universal e fores iluminado por sua sombra, ali verás o mais admirável de todo admirável.

IBN GABIROL, Fons Vitae, V, 42.

IBN GABIROL, Fons Vitae, V, 10

Ver quanto a este aspecto BRUNNER, F. "La doctrine de la matière chez Avicébron", Revue de Théologie et de Philosophie. Lausanne, 3 (1956), p. 272-3. 
Dedica-te e dirige-te a isso, pois é o objetivo da alma humana e ali residem a grande delícia e a maior felicidade". ${ }^{41}$

Embora a estrutura subjacente à metafísica de Ibn Gabirol, ou seja, a das emanações possa ser atribuída a uma influência do pensamento de Plotino e que certas semelhanças gerais e de linguagem possam aproximar estes dois autores, as diferenças, em termos de formulação, bem como o tratamento conferido às realidades geradas pelas hipóstases (que, em Gabirol, assumem a denominação aristotélica de substâncias), conduzem a outro tipo de conexões. A estrutura das emanações não é exclusividade do pensamento plotiniano e elementos fundamentais do pensamento de Gabirol, como a necessidade de intermediação entre a Essência Primeira e as realidades criadas compostas de matéria e forma, aproximam-no muito mais de seu co-religionário alexandrino Filon, bem como de Proclo e Jâmblico ${ }^{42}$ do que daquele filósofo.

\section{A influência aristotélica}

Ainda que os diversos estudiosos de Ibn Gabirol tenham percebido a importante influência de Aristóteles, muitos optaram por legá-la a segundo plano em seus estudos. Acreditamos que esta opção tenha sido realizada provavelmente pela dificuldade em estabelecer, historicamente, com segurança, o meio de transmissão dessas idéias. Assim, S. Munk, por exemplo, embora apontasse que

a influência das doutrinas de Aristóteles se mostra em todos os lugares na filosofia de Ibn Gabirol, ela é manifesta demais para que nós tenhamos necessidade de demonstrá-la. A doutrina da matéria e da forma, considerada sob o ponto de vista de Aristóteles domina todo o sistema de nosso autor; a lógica do Estagirita desempenha um papel importante, sua física e sua metafísica deixaram numerosos traços. ${ }^{43}$

No entanto, Munk terminou por optar por relacionar a obra do autor prioritariamente a Plotino e aos Alexandrinos. Muito provavelmente isso decorre do fato de que a maioria dos estudiosos medievalistas aponte Ibn Badjja como o introdutor das obras de Aristóteles na Península Ibérica. Como isso só poderia ter ocorrido seguramente após a morte de Gabirol, o fato gera um problema sério de datas. De acordo com os estudiosos, a filosofia de Ibn Sina ainda tinha alcance restrito, na época, e seria perigoso atestar seguramente o conhecimento das obras de AlFarabi na Espanha de Al-Andalus. Acreditamos que essa tenha sido a razão fundamental para que tão pouca atenção tenha sido dedicada à forte presença aristotélica no texto até mais recentemente. De novo, conforme Munk,

\footnotetext{
IBN GABIROL, Fons Vitae, III, 57.

42 Como a idéia discutida por MATHIS II, C. K. "Parallel Structures in the Metaphysics of Iamblichus and Ibn Gabirol". In GOODMAN, Lenn (Org.), Neoplatonism and Jewish Thought. Studies in Neoplatonism: Ancient and Modern, vol. 7. New York: State University of New York Press.

${ }^{43}$ MUNK, op. cit., p. 234.
} 
o peripatetismo não exercia ainda nas Escolas árabes esta autoridade absoluta que irá conquistar Ibn Sina, morto em 1037, e cujas obras eram ainda pouco conhecidas, sobretudo na Espanha, quando Ibn Gabirol escreveu sua Fonte da Vida. Eram estudados, sobretudo, os comentadores neoplatônicos de Aristóteles e certas obras apócrifas, onde a doutrina do Estagirita estava submersa nos devaneios provenientes da Escola de Alexandria. ${ }^{44}$

A influência de Al-Kindi já é amplamente presente no pensamento de Isaac Israeli, representando ambos os autores possíveis fontes de Ibn Gabirol. Por outro lado, já foi levantada na literatura a possível influência de Avicena, ${ }^{45}$ mas tendemos a concordar com Chouraqui, quando nos diz que "todo o sistema da Fonte da Vida é dominado pela doutrina aristotélica da matéria e da forma; a lógica, a física e a metafísica de Aristóteles penetram as articulações do pensamento de Ibn Gabirol, familiarizado, sem dúvida, com as obras de Al-Farabi" . . Assim, a nosso ver, o Fons Vitae surge de uma inspiração platônica expressa numa linguagem fortemente aristotélica, como uma obra de todo inserida no seu contexto filosófico: o de compatibilização da obra dos mestres gregos pelos pensadores islâmicos. A apropriação que Gabirol faz da doutrina aristotélica não se resume aos termos matéria, forma e substância, e nem mesmo às categorias que porventura poderia ter trazido da Isagoge de Porfírio. A estrutura lógica de demonstração utilizada no Tratado Terceiro vai muito além, sugerindo que ele tivesse acesso ao Organon ou a comentários ao corpus aristotélico, o que, por sua vez, descartaria definitivamente a mera adaptação de uma linguagem neoplatônica pagã, e se encaixaria muito melhor como versão judaica de um corpus filosófico islâmico de filiação aristotélica.

Os pontos derivados da doutrina de Aristóteles são muitos, e começam com a questão da própria matéria universal. Conforme Celina Lértora,

notemos alguns pontos de concordância com o Aristotelismo histórico: a matéria universal (como a matéria prima) é numericamente una para todos os seres. Parece, pois, que Ibn Gabirol chegou à sua noção de matéria universal, do ponto de vista filosófico, por uma universalização da matéria primeira da Physica aristotéli$\mathrm{ca}^{47}$

O tratamento conferido também à "substância" não parece ter outra origem. Passagens como a em que ele explica ao discípulo a equivalência dos termos substância e matéria e a especificidade destes termos, quando se referem ao seu

${ }^{44}$ MUNK, op. cit., p. 235.

45 "Primeiro ele adotou, provavelmente da tradição Aviceniana, uma completa doutrina de matéria e forma. Nessa, não somente fez uma série de formas específicas se sobreporem à forma básica do corpo (forma corporeitatis), como, para usar uma comparação despretensiosa, as várias camadas de uma cebola: essa, a pluralidade de formas não era, de modo algum, uma doutrina nova" (KNOWLES, David. The Evolution of Medieval Thought. London: Longman, 1988, p. 184).

46 CHOURAQUI, A. La Couronne Du Royaume de Salomon Ibn Gabirol. Institut International d'Études Hébraiïques, Mélanges de Philosophie et de Littérature Juives, 1-2. Paris: P.U.F., 1956-1957, p. 277.

47 LÉRTORA MENDOZA, Celina Ana. El Legado de Sefarad: Temas de Filosofía Sefardí. Buenos Aires: Editorial Sefarad 92. 1999, p. 49. 
significado como substrato da forma ou à matéria desprovida daquela, parecem explicações didáticas de trechos aristotélicos, como a seguinte afirmação: "Como a substância no significado de substrato e de matéria é admitida por todos..."48 Sem dúvida, o conceito de substância é um dos pontos fundamentais da teoria gabiroliana, tanto como categoria puramente metafísica, enquanto composto de matéria e forma, equivalente ao sínolo aristotélico, quanto como categoria lógica. Na sua utilização, enquanto categoria metafísica, a substância é estendida até abarcar o mundo supra-sensível, tanto o supralunar, como já o fizera Aristóteles, como todo o mundo inteligível, numa manobra que praticamente exclui de seu modelo o termo Idéia. Exceção deve ser feita à matéria universal e à forma universal. Essas são tratadas como Idéias, no sentido de inteligíveis universais, e aqui vemos certo retorno ao platonismo. Nesse sentido, podemos observar que ele talvez se insira no movimento comum à época, ou seja, mais do que numa compatibilização entre Platonismo e Aristotelismo, na identificação de uma filosofia comum e seqüenciada. Quanto a isso, sabemos que, tanto Al-Farabi quanto Ibn Sina, pela atribuição do Liber de Causis e da Teologia a Aristóteles, conceberam uma doutrina mista, expondo as doutrinas emanacionistas que compunham esses livros em moldes de linguagem aristotélica, acreditando estar sendo fiéis ao Estagirita.

A questão das substâncias simples, que foi normalmente identificada com o texto árabe do Pseudo-Empédocles sobre as cinco substâncias, pode ser assim também uma derivação adaptada de uma leitura neoplatônica da Metafísica de Aristóteles, ou ainda uma composição entre as duas fontes, conforme tentaram alguns de seus contemporâneos islâmicos. Embora a idéia do encadeamento Inteligência - Alma - Natureza possa conduzir à impressão de que esta seja uma mera adaptação da estrutura das hipóstases de Plotino, o fato de estas realidades serem denominadas e tratadas como substâncias remete-nos mais uma vez ao texto da Metafísica. No livro décimo segundo, Aristóteles expõe os diferentes sentidos em que o termo substância é utilizado, abrindo espaço para as substâncias inteligíveis, quando afirma:

Existem três substâncias. Uma é a substância sensível, que se distingue em eterna e corruptível (...) A outra substância é imóvel, e alguns filósofos afirmam que ela é separada; alguns a separam ulteriormente em dois tipos, outros reduzem as Formas e os Entes matemáticos a uma única natureza; outros, ainda, só admitem os Entes matemáticos. ${ }^{49}$

A utilização das categorias também é um indício de seu conhecimento. As categorias, para Gabirol, são gêneros da substância corporal. ${ }^{50}$ Mas, trabalhando

\footnotetext{
ARISTÓTELES. Metafísica. São Paulo: Loyola, 2005, H, Livro oitavo, 2 (1042b), p. 371.

ARISTÓTELES, Metafísica, $\Lambda$ (Livro décimo segundo), 1 (1069a).

Como podemos notar através da fala do discípulo, que se refere às categorias como gêneros: "Mas, resta-me uma dúvida, pois se digo que todas as formas corporais estão nas espirituais de uma maneira mais simples que na substância corpórea, e que o inferior é imagem do superior e nele se en-
} 
com o conceito de "cosmo inteligível", proveniente de Fílon, como esse não estaria restrito à Inteligência, mas sim ao conjunto das substâncias espirituais simples, não há razão para que o modelo gabiroliano não vá além, advogando um paralelismo perfeito entre aquele e o universo sensível. Esse perfeito paralelismo entre o cosmo inteligível (conjunto das substâncias espirituais) e o universo sensível, aponta para uma correspondência necessária entre ambas as facetas da criação que é expressa, não somente através da composição hilemórfica compartilhada, mas também na possibilidade de aplicação de equivalentes lógicos das categorias aristotélicas ao mundo superior: ${ }^{51}$

Observa a extremidade inferior do ser, isto é, cada um dos gêneros dos que estão no extremo inferior e observa também a extremidade superior. Encontrarás para cada um dos gêneros que se encontra na extremidade inferior algo que lhe seja oposto no extremo superior. Encontrarás a matéria universal frente à substância, a quantidade frente à forma da inteligência, como foi demonstrado pelo que antes dissemos. Também a encontrarás igualmente frente às unidades que se sustentam nas formas das substâncias; também encontrarás igualmente as sete espécies simples da quantidade frente ao número sete das substâncias simples, isto é: matéria, forma, inteligência, almas e natureza e frente ao número das forças de cada uma destas substâncias; encontrarás a qualidade frente às diferenças destas substâncias e suas formas, e encontrarás a relação frente ao ser delas enquanto causa e causado; encontrarás o tempo frente à eternidade e encontrarás o lugar frente à ordem destas substâncias em sua anterioridade e posterioridade, e encontrarás a situação frente à subsistência e encontrarás o agente frente àquilo que nessas substâncias, imprime, designa e cria; encontrarás o paciente frente àquilo que é impresso nessas substâncias; encontrarás o modo de ser frente ao ser da forma universal na matéria universal e frente ao ser de qualquer das formas da substância simples na matéria que a sustenta, e frente ao ser das forças próprias a cada uma das substâncias em si mesmas. Não vês, por estas coisas, o que antes te disse, ou seja, a partir da oposição que há entre as formas da substância composta e as formas da substância simples, que as formas da substância composta emanam das formas da substância simples? ${ }^{52}$

Em termos de substâncias espirituais, existe, portanto, uma seqüência de propriedades que, de acordo com Gabirol, podem ser dispostas ao lado das categorias, enquanto equivalentes lógicos, mas pertencentes a uma oitava superior. Isso não significa que Ibn Gabirol desconhecesse que a aplicabilidade das categorias aristotélicas fosse restrita à substância corpórea. Mas, assim como estabelece a ampliação do hilemorfismo a toda a realidade, à exceção da Essência Primeira e sua Vontade, Gabirol estabelece um paralelo perfeito entre o conjunto das coisas

contra, como podem estar os dez gêneros corporais na substância espiritual?" (IBN GABIROL, Fons Vitae, III, 27).

51 Essa é, então, mais uma das diferenças fundamentais que Gabirol mantém para com Plotino o qual afirma que as categorias aristotélicas não podem ser aplicadas ao cosmo inteligível, ao qual devem ser atribuídas outras, retiradas do Sofista de Platão: o ser, o repouso, o movimento, a identidade e a diversidade.

52 IBN GABIROL, Fons Vitae, III, 27. 
sensíveis e o conjunto dos inteligíveis, o que é perfeitamente compreensível, dado que está tratando de realidades as quais denominou, da mesma maneira, substâncias.

Entre outras passagens surge a noção de definição. Se, para Aristóteles, para poder definir algo, são necessários o gênero e a diferença, encontramos o paralelo exato em Ibn Gabirol, quando nos diz que "porque se unem os seres simples, isto é, o gênero e a diferença com sua essência, e então se completa para ela o conhecimento do ser da coisa, isto é, a definição". ${ }^{53}$ Ou quando nos fala a respeito da matéria e da forma universais, cuja "definição não é possível; pois não há incidindo sobre elas gênero algum que possa servir de princípio para sua definição". ${ }^{54}$ Temos aqui então mais um indício de que Ibn Gabirol não conheceu apenas o texto de Porfírio, ou alusões esparsas acerca da lógica. Reafirmamos, uma vez mais, que, de alguma maneira, ele teve acesso ao conteúdo do Organon. Outras passagens também nos chamam a atenção, como, por exemplo, sua explicação acerca da unidade e da multiplicidade, que concorda com Aristóteles, quando nos diz: "Cada número é muitos porque é constituído de muitas unidades e é mensurável ao um porque é oposto ao um e não ao pouco". ${ }^{55}$

Até a discussão da necessidade do intermediário entre a Essência Primeira e a realidade criada, composta de matéria e forma, a qual é a base da defesa do Princípio supremo criador (a Vontade) e que, conforme dissemos anteriormente, poderia ter surgido por uma inspiração gerada pelo Lógos de Fílon de Alexandria, pode também ter surgido simplesmente de uma necessidade lógica por igual derivada das questões apresentadas na Metafísica. Acreditamos que a forma sob a qual Ibn Gabirol apresenta esta questão pende mais para a segunda hipótese, apresentando-se como uma adaptação da seguinte passagem aristotélica: "Como entre os contrários pode haver um termo intermediário, e, nalguns casos, efetivamente há, é necessário que esses termos intermediários sejam compostos dos contrários" ${ }^{56}$

\section{0 rótulo}

Se tivéssemos, necessariamente, que escolher um rótulo ${ }^{57}$ e conferi-lo a Ibn Gabirol, classificaríamos o autor como neo-platônico, posto que o urdume inicial sobre o qual sua teoria é tecida corresponde a uma estrutura de emanações sucessivas na qual as realidades inteligíveis são modelos para as realidades sensíveis. Mas sempre entendendo que essas classificações são relativas, dado que alguns

\footnotetext{
IBN GABIROL, Fons Vitae, III, 41.

IBN GABIROL, Fons Vitae, V, 22.

ARISTÓTELES, Metafísica, I (Livro Décimo), 6 (1056b).

ARISTÓTELES, Metafísica, I (Livro décimo), 7 (1057a).

"Os filósofos judeus medievais são costumeiramente divididos em quatro grupos: Mu'tazilis, Mutakallimun, Neoplatônicos, Aristotélicos de vários tipos e críticos do Aristotelismo". (HYMAN, Arthur, Medieval Jewish Philosophy as philosophy, as Exegesis and as Polemic. In Miscellanea Mediaevalia ed. Jan A. Aertsen, Band 26: Was ist Philosophie im Mittelalter. Berlin: Walter de Gruyter, 1998, p. 251).
} 
filósofos aceitam a base de um dos tipos de pensamento, mas rejeitam partes importantes de suas doutrinas. Cabe ressaltar, igualmente, que entendemos aqui neo-platônico em sentido amplo, ou seja, um seguidor da proposta de Platão modificada por outras influências e desenvolvimentos filosóficos posteriores.

Se, por um lado, conforme já indicamos, é notório algum conhecimento, por parte de Ibn Gabirol, das idéias provenientes das Enéadas de Plotino, são também notáveis as diferenças que podemos estabelecer entre os dois sistemas de pensamento. Estes, a nosso ver, consistem em metafísicas consideravelmente distintas e, em alguns casos, contraditórias. Muito distante do panteísmo plotiniano do qual foi acusado, cremos que Ibn Gabirol parte originariamente de sua formação judaica; são as crenças específicas dessa tradição monoteísta que ele tentará defender, através da racionalidade filosófica. Com o hilemorfismo universal aplicado a toda a criação, mas somente à criação - o que lhe garante a sustentação da dessemelhança radical entre Deus e o mundo bem como a finitude do criado - e com a teoria da Vontade, assegurando a criação por pura liberdade e graça divinas, Gabirol transforma o sistema neoplatônico de emanações num dualismo. Neste, acima de tudo, há a Essência Primeira, que a nada é comparável, e, abaixo, a totalidade do criado que mantém a semelhança pela invariabilidade da composição hilemórfica. Conforme Celina Lértora, "como se vê, a explicação emanatista, que determina um universo homogeneamente descendente, resulta aplicável à criação, ao criado, mas não à totalidade do existente. O monismo transformou-se em dualismo". ${ }^{8}$

Por mais estranho que pareça, à primeira vista, diversos elementos que vieram a garantir a ortodoxia judaica (ainda que muito peculiar) a esse conjunto, na obra de Ibn Gabirol, parecem ser provenientes da contribuição aparentemente mais alienígena: precisamente aquelas idéias formuladas em linguagem aristotélica, transmitidas provavelmente por fontes islâmicas. O modo de assegurar a absoluta separação entre Deus (Ein Sof) e criação é fornecido aqui precisamente pelo modelo hilemórfico e pela existência de um intermediário, semelhante tanto a Deus quanto à criação. Por sua vez, a absoluta liberdade criativa é garantida também através desse intermediário criador, uma vez que ele é entendido enquanto livre Vontade de Deus. Para evitar de cair na armadilha do Deus segundo, é o jogo potência/ato que é invocado, posto que se, em essência, a Vontade é inseparável de Deus, o mesmo não ocorre frente a seu efeito, ou seja, a criação. Desse modo, a Vontade criadora, ainda que unida a Deus enquanto atributo, para que mantenha alguma semelhança com o criado, que é seu efeito, é separada da Essência divina em ato.

58 LERTORA MENDOZA, Celina, op. cit., p. 50. 